\title{
AMINOSILICA NANO- AND SUBMICROSPHERES: ANALYSIS OF FACTORS INFLUENCING MORPHOLOGY, STRUCTURE AND PROPERTIES
}

\author{
Inna Melnyk \\ Chuiko Institute of Surface Chemistry of NAS of Ukraine, 17, General Naumov str., Kyiv 03164, Ukraine \\ e-mail: melnyk@isc.gov.ua; phone:(+38) 04442296 09; fax: (+38) 0444243567
}

\begin{abstract}
Current paper focuses on the analysis of influence of main factors (stages of the synthesis, the ratio of the reacting components, the order of their introduction, the concentration of water and ammonia, the synthesis temperature) on the morphology, size and content of functional groups of aminosilica nano- and submicrospheres. The recommendations for the synthesis of particles with predetermined properties were done. It is shown, that the ratio of the reacting components mainly affects the content of 3-aminopropyl functional groups and the temperature of the hydrolytic polycondensation reaction - the size of the particles.
\end{abstract}

Keywords: silica nanoparticles and submicrospheres, aminopropyl groups, Stöber method.

\section{Introduction}

Silica nanoparticles are prominent in research, as they are easy to synthesize and are widely used in various fields such as catalysis [1], adsorption (including adsorption of pigments) [2], medicine [3], manufacturing of electronic and thin supports, and electronic insulation materials [4]. The quality of most of these products is largely dependent on the size and size distribution of the particles and the nature, content, and stability of their functional groups. The formation of silica nanoparticles and their size are controlled by the rate of two reactions: alkoxysilanes hydrolysis to form oligomers with silanol groups $\mathrm{Si}(\mathrm{OR})_{4}+\mathrm{H}_{2} \mathrm{O} \rightarrow \mathrm{Si}(\mathrm{OH})_{4}+4 \mathrm{ROH}$, and condensation of oligomers to form siloxane bonds $2 \mathrm{Si}(\mathrm{OH})_{4} \rightarrow 2(\mathrm{O}-\mathrm{Si}-\mathrm{O})+4 \mathrm{H}_{2} \mathrm{O}$.

In 1968 Stöber et al. described the synthesis of monodisperse spherical silica nanoparticles by hydrolytic polycondensation of silicon alkoxides in aqueous alcohol solutions in the presence of ammonia [5]. So, there were synthesized silica particles ranging in size from $50 \mathrm{~nm}$ to 1.5 microns with narrow size distribution. In the same publication, it was shown that with increasing concentration of ammonia, the size of silica particles decreases. With respect to the concentration of water and alcohol, it was necessary to select specific conditions. Later [6], there was determined the effect of temperature and the nature of solvent on the particle size, and in [7] - the impact of the components ratio and components addition order during the reaction. Thus, so far, there were suggested techniques for obtaining silica nanoparticles and some of the factors that affect their properties were determined.

Functionalization of surfaces of such materials significantly extends their applications. Recently, more and more silica microspheres, especially containing 3-aminopropyl groups are used for adsorption of biomolecules [8] and metal ions [9]. This is due to the participation of amino groups in hydrogen bonds and the formation stable metal complexes. It is not surprising, that already in the $1990^{\text {th }}$, there appeared publications about functionalization of silica particles [10-12]. However, there still lacks the systematization of the material, and there are no answers to such important questions as which ratios of ingredients, temperature, amount of catalyst, etc. should be used to obtain silica particles of a certain size and with the required content of functional groups. Therefore, the subject of this paper is such analysis.

\section{Methods of synthesis: one-step and two-steps}

The search for the techniques of synthesis of spherical silica particles with 3-aminopropyl groups in their surface layers was launched in [10]. Some authors suggested two- (scheme 1) and single-stage (scheme 2) [11] techniques.

The two-stage method included the formation of pure silica nanoparticles (either extracted or not from their reaction solution) with their subsequent modification with 3-aminopropyl groups. For example, Badley et al. first prepared silica nanoparticles in water-ethanol-ammonia solution, then the solvent was removed and the reaction between silica and 3-aminopropyltrimethoxysilane (APTMS) was held in DMF by heating to $100^{\circ} \mathrm{C}$. Such sample contained 0.81 $\mathrm{mmol} / \mathrm{g}$ of amino groups at components ratio $\sim 4 / 1$ ( $\mathrm{SiO}_{2} / \mathrm{APTMS}$ ) [10]. Using the same ratio of alkoxysilanes in waterethanol-ammonia solution, Badley et al. also prepared sample with groups content of $0.61 \mathrm{mmol} / \mathrm{g}$, firstly adding TEOS to the reaction mixture, and after $5 \mathrm{~h}$ - APTMS. Moreover, the stirring with APTMS was accompanied by ultrasonic treatment for $20 \mathrm{~h}$ [10]. Scientists [2] also produced spheres via two-stage method. But the presence of amino groups in them was not proved, their content was not specified and the TEOS/APTES (3-aminopropyltriethoxysilane) ratio was $\sim 500$. Blaaderen et al. in [11], except for one-stage synthesis, also conducted surface modification of silica particles. Modification was carried out at TEOS/APTES ratios equal to $1 / 3$ and $\sim 1 / 1$, by the addition of APTES to alkosol and stirring the mixture for $1 \mathrm{~h}$ at room temperature followed by boiling for $2 \mathrm{~h}$ and partial stripping of the solvent. Thus, the 
authors obtained particles of 9 and $\sim 70 \mathrm{~nm}$ in size, but only the former (according ${ }^{29} \mathrm{Si}$ MAS NMR spectroscopy data) contained $\mathrm{T}^{3}$ and $\mathrm{T}^{2}$ structural units, indicating a consolidation of functional groups on the surface of these particles, according to elemental analysis their content was $1.5 \mathrm{mmol} / \mathrm{g}$.

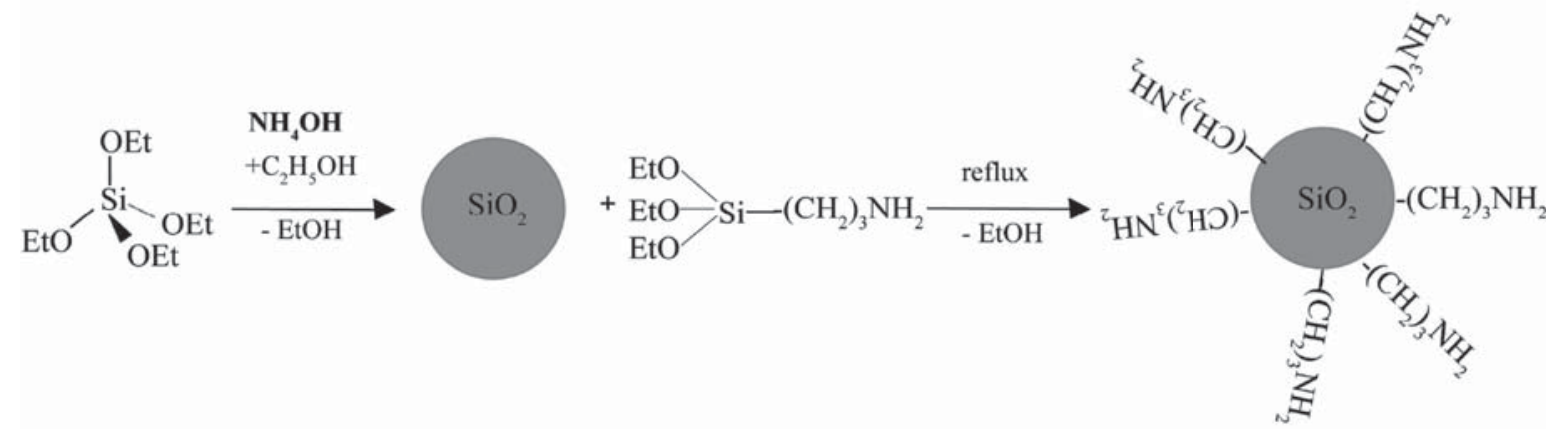

Scheme 1. Two-steps synthesis of functionalized silica nanoparticles.

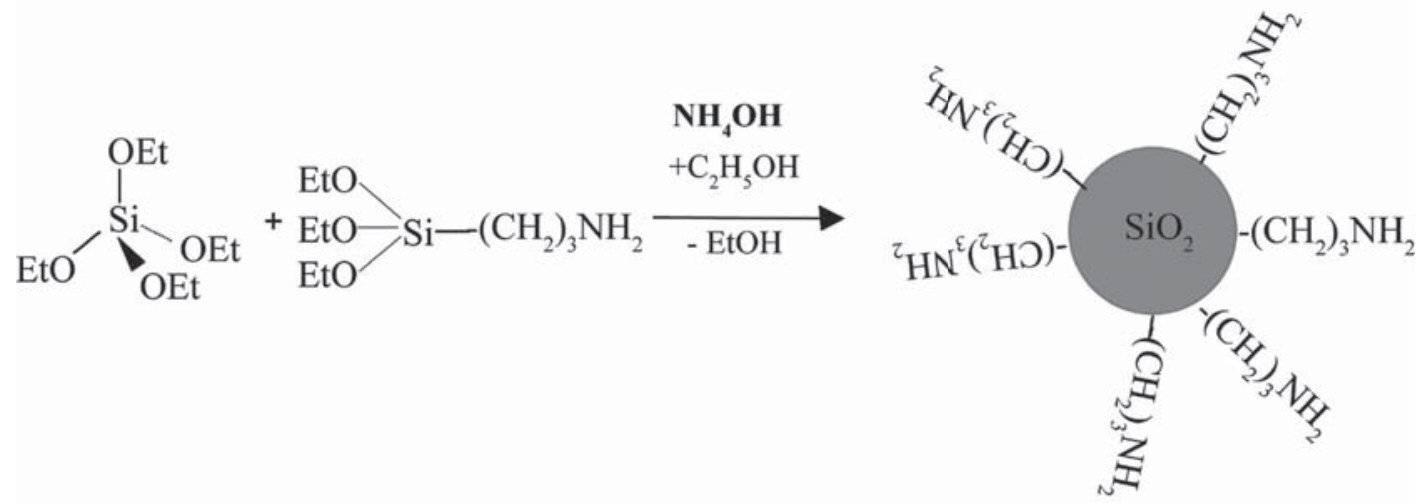

Scheme 2. One-step synthesis of aminofunctionalized silica nanoparticles.

We performed similar syntheses (surface modification of nanoparticles using APTES) at room temperature, but according to IR spectroscopy and acid-base titration did not observe the presence of amino groups in the particles [13]. However, authors in [14] describe the preparation of silica particles with amino groups at room temperature. Thus, the suspension of synthesized silica particles initially was stirred for $24 \mathrm{~h}$, and after that, another $24 \mathrm{~h}$ with APTES (ratio of components was 1/1). The content of functional groups was not determined, but they were identified by ${ }^{13} \mathrm{C}$ and ${ }^{29} \mathrm{Si}$ MAS NMR spectroscopy.

One-step method of synthesis was also considered in [11], where alkoxysilanes (first APTES, and after 1min TEOS) at a ratio of about 1/1 were added to water-ethanol-ammonia solution. The resulting particles were about $100 \mathrm{~nm}$ in size with $3.2 \mathrm{mmol} / \mathrm{g}$ of amino groups. That is, there was developed one-step method of obtaining silica nanoparticles with high content of 3-aminopropyl groups. However, the sample contained both spherical particles, and non-spherical impurities [13]. Therefore, we examined in more detail the peculiarities of obtaining silica particles with 3-aminopropyl functional groups. It was established that the addition of APTES to ethanol-ammonia solution containing already formed silica particles does not lead to the fixation of amino groups on their surface. This requires boiling of the suspension or changing of the sequence alkoxysilanes introduction (first APTES and then TEOS). Moreover, it was stated in [12] that stirring APTES in water-ethanol-ammonia solution does not result in visible changes of the reagent, and adding TEOS after stirring for $24 \mathrm{~h}$ forms a gel-like substance.

\section{The variation of the ratio of the reaction components}

References of such specifically conducted research were not found. But in the paper [11], changing the components ratio from $1 / 3$ to $1 / 1$ determined the decrease in the particle size from $\sim 10 \mathrm{~nm}$ to $\sim 70 \mathrm{~nm}$ and the drop in the contents of amino groups from $3.2 \mathrm{mmol} / \mathrm{g}$ to $0.2 \mathrm{mmol} / \mathrm{g}$ (at the margins of the experimental error) in obtaining two-stage particles. Thus, it is clear that amino groups, having basic properties, affect the size of the obtained particles. In [12], it was shown that for one-stage synthesis under the same conditions an increase in particle size - $120 \mathrm{~nm}$, $140 \mathrm{~nm}$ and $182 \mathrm{~nm}$ was observed by changing the component ratio from 1.5/1, 2/1 to 3/1, respectively. Our research 
[13] confirmed such trend (Figure 1). Moreover, it was found, that the increase in the molar ratio of TEOS/APTES also improves morphological characteristics of the samples. However, the content of functional groups significantly decreased with increasing ratio to $6 / 1$.

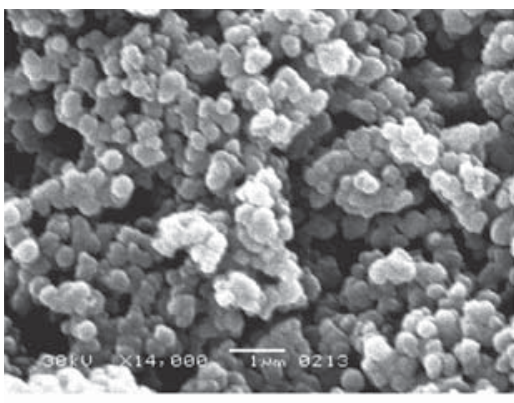

$1 / 1-200 \mathrm{~nm}, 2.1 \mathrm{mmol} / \mathrm{g}$

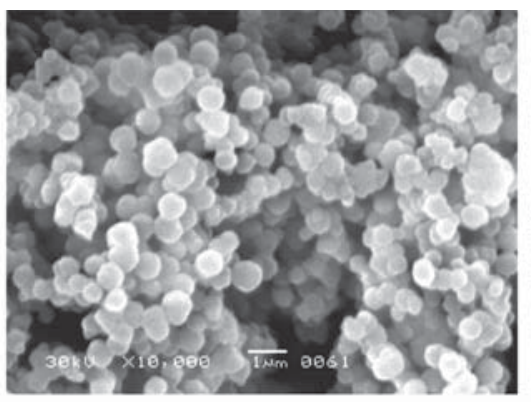

$3 / 1-400 \mathrm{~nm}, 1.3 \mathrm{mmol} / \mathrm{g}$

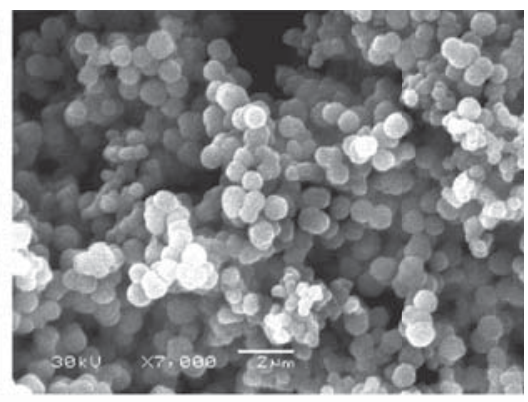

$6 / 1-700 \mathrm{~nm}, 0.3 \mathrm{mmol} / \mathrm{g}$

Figure 1. The influence of the ratio of reacting of alkoxysilanes (TEOS/APTES).

\section{Effect amount of water and ammonia on the morphology and concentration of 3-aminopropyl groups}

Some authors believe, that the amount of water in the synthesis must be greater [10,11], and others - that the water from ammonia solution is sufficient for the reaction of hydrolytic polycondensation [12]. Our studies have shown [13] that the extra amount of water does not affect the particle size and the content of functional groups.

In $[5,7]$ the influence of the concentration of water and ammonia was considered in detail for silica nanoparticles (Figure 2). From this figure, it is evident that if there is a direct dependence between particle size and concentration for the ammonia, initially increasing concentration of water promotes the increase in particle size, followed by its sudden decrease. In addition, it was noticed that heterodispersed particle size distribution is observed in small quantities of alcohol. As for particles with 3-aminopropyl groups, it should be noted that the amino group itself creates an alkaline environment. In addition, the order of adding ammonia as a catalyst to the reaction solution is also very important. When ammonia is injected into the water-ethanol solution before alkoxysilyl components, APTES should be added first, or the synthesis should be conducted with heating, otherwise, amino groups would not be fixed on the surface of particles $[10,11]$. However, co-condensation of two alkoxysilanes (TEOS and APTES) can be used to form aminospheres at room temperatures by mixing components and adding ammonia as a catalyst to this mixture [12]. We also showed that silica microspheres with 3-aminopropyl groups formed without the use of ammonia [13]. Adding ammonia only improved particle size distribution, the content of functional groups did not change (Figure 3), but the size of the formed particles increased. Therefore, there was not observed simple dependence between the concentration of ammonia and particle size for aminosilica.

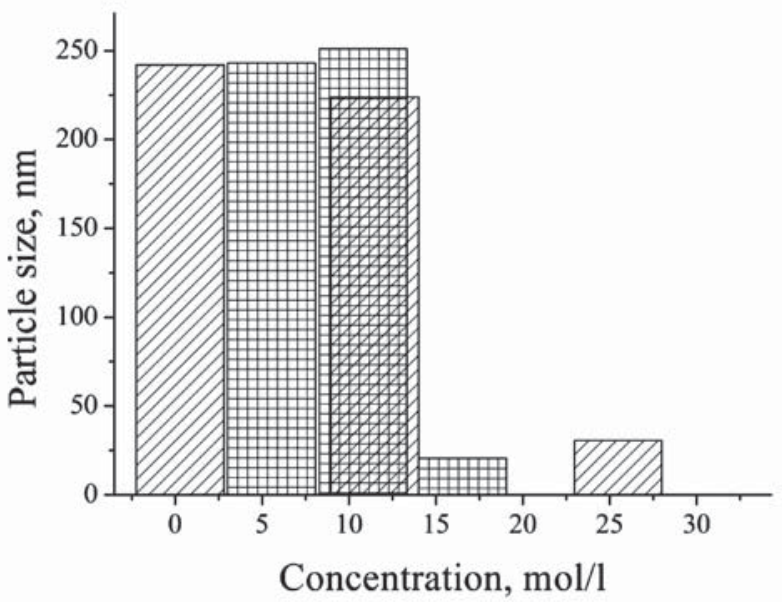

Figure 2. The effect of ammonia (lines) and water (cells) on silica particle size [7]. 


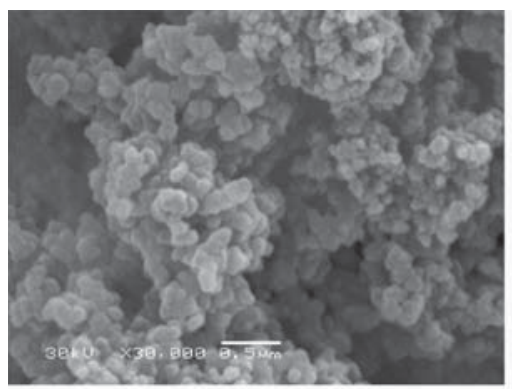

TEOS/APTES=1/1, without $\mathrm{NH}_{4} \mathrm{OH}, \mathrm{C}_{\mathrm{tg}}=2.1 . \mathrm{mmol} / \mathrm{g}$

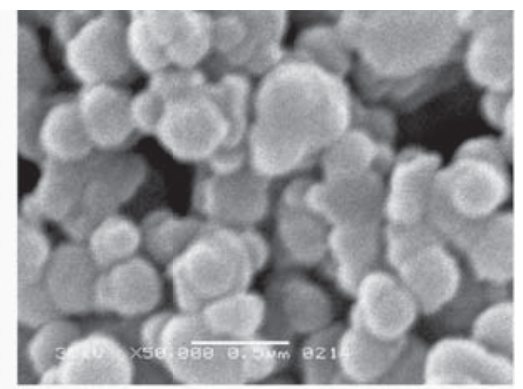

TEOS/APTES $=1 / 1,0.14 \mathrm{M} \mathrm{NH}_{4} \mathrm{OH}, \mathrm{C}_{\text {f.p. }}=2.1 . \mathrm{mmol} / \mathrm{g}$

Figure 3. The effect of ammonia for aminosilica particles.

\section{Effect of synthesis temperature}

As shown in Figure 4 [6], the particle size decreases with increasing temperature for the silica particles. The most important result is that silica spheres can be synthesized in a wide size range $(0.2-2.0 \mu \mathrm{m})$ using TEOS and alcohol solvent by changing the reaction temperature. The synthesized particles are relatively monodisperse and size distribution becomes broader with increasing temperature. Other authors [7] extended these studies and the effect of temperature on the particle size of the silica was studied at different concentrations of ethanol. These comparative studies were conducted from 30 to $70^{\circ} \mathrm{C}$. The authors concluded that the particle size increases with increasing temperature in less dilute solutions (solvent - ethanol), respectively, reducing the particle size was observed with increasing temperature in the more dilute solutions [7]. These dependencies are represented in the literature for aminosilica particles. Only [10] refers to the fact that heating the suspension to $100^{\circ} \mathrm{C}$ for $24 \mathrm{~h}$ does not contribute to the consolidation of more groups on the surface but contributes to the stability of the surface layer by modifying silica particles with APTES.

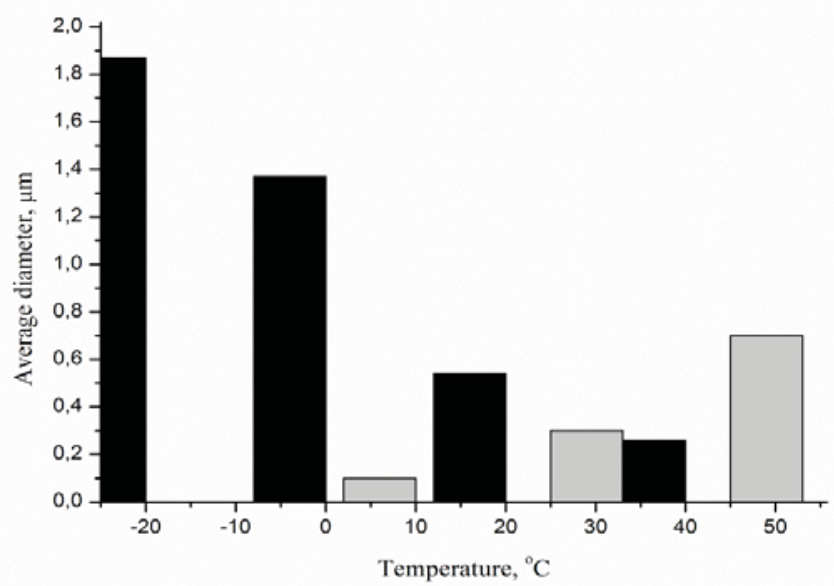

Figure 4. The average diameter of silica spheres (black) [6] and aminosilica spheres (gray) obtained using different temperatures.

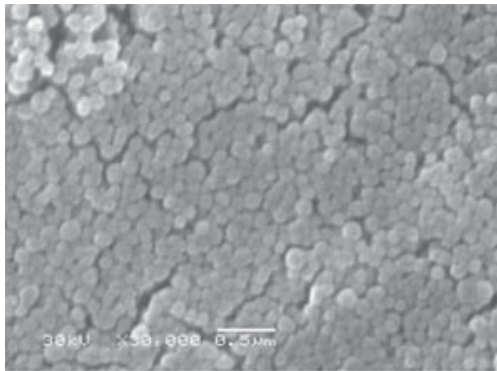

$2^{\circ} \mathrm{C}, 100 \mathrm{~nm}$

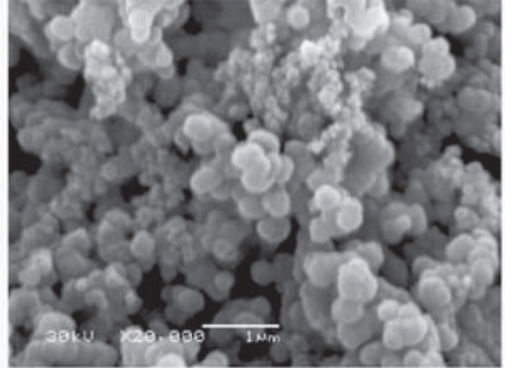

$25^{\circ} \mathrm{C}, 300 \mathrm{~nm}$

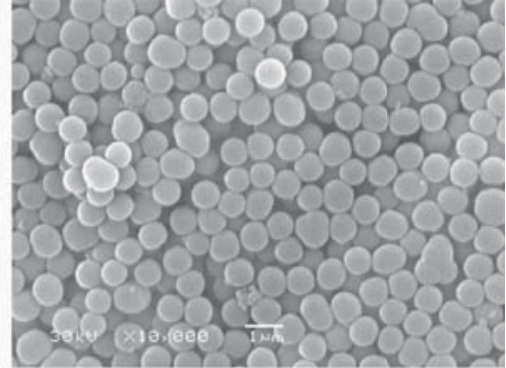

$45^{\circ} \mathrm{C}, 700 \mathrm{~nm}$

Figure 5. SEM images of aminosilicas at different temperatures. 
We studied the influence of the synthesis temperature on particle size and content of functional groups. The synthesis was performed by mixing alkoxysilanes and adding ammonia after the appearance of opalescence at different temperatures $-2^{\circ} \mathrm{C}, 25^{\circ} \mathrm{C}$ and $45^{\circ} \mathrm{C}$ [13]. Comparing these samples to their size (Figure 5), it is easy to conclude that the increase in temperature of an ice bath $\left(\approx 2^{\circ} \mathrm{C}\right)$ to $45^{\circ} \mathrm{C}$ leads to the 7 times increase in the diameter. This increases the content and functional groups.

\section{Conclusions}

There was analyzed the influence of such factors as components addition order, reacting alkoxysilanes ratio, temperature, amount of water and solvent on the morphology and functional groups content in aminosilica microspheres. It was determined, that contrary to "pure" silica spheres, ammonia has no decisive influence on the particle size of aminosilica microspheres, and there is an inverse temperature relationship: namely, with growing temperature, particle size is not decreasing but increasing. Two-component system TEOS/APTES significantly differs from one-component because here the formation of functionalized particles can occur without introducing ammonia solution. Modification of silica particles with 3-aminopropyltriethoxysilane in ammonia-alcohol solution does not lead to fixation of the groups on the surface of silica particles (at room temperature), because the processes of condensation dominates over hydrolysis in alkaline environment. It was shown that the synthesis temperature has a significant impact on the shape and size of the particles, and the ratio of the reacting alkoxysilanes on the content of the 3-aminopropyl groups.

\section{Acknowledgments}

This work was carried out within the framework to the State Target Scientific and Technical Program of NASU "Nanotechnologies and Nanomaterials" (project No 6.22.5.42).

\section{References}

1. Banerjee, S.; Santra, S. Remarkable catalytic activity of silica nanoparticle in the bis-Michael addition of active methylene compounds to conjugated alkenes. Tetrahedron Letters, 2009, 50(18), pp. 2037-2040.

2. Wu, Z.; Xiang, H.; Kim, T.; Chun, M.-S.; Lee, K. Surface properties of submicrometer silica spheres modified with aminopropyltriethoxysilane and phenyltriethoxysilane. Journal of Colloid and Interface Science, 2006, 304, pp. 119-124.

3. Knopp, D.: Tang, D.; Niessner, R. Review: Bioanalytical applications of biomolecule-functionalized nanometersized doped silica particles. Analytica Chimica Acta, 2009, 647, pp. 14-30.

4. Aspen Aerogels. http://www.aerogel.com/ehs.html.

5. Stöber, W.; Fink, A.; Bohn, E. Controlled growth of monodisperse silica spheres in the micron size range. Journal of Colloid and Interface Science, 1968, 26, pp. 62-69.

6. Tan, C.G.; Bowen, B.D.; Epstein, N. Production of monodisperse colloidal silica spheres: effect of temperature. Journal of Colloid and Interface Science, 1987, 118(1), pp. 290-293

7. Rao, K. S.; El-Hami, K.; Kodaki, T.; Matsushige, K.; Makino, K. A novel method for synthesis of silica nanoparticles. Journal of Colloid and Interface Science, 2005, 289, pp. 125-131.

8. Enrichi, F. Luminescent amino-functionalized or erbium-doped silica spheres for biological applications. Annals of the New York Academy of Sciences, 2008, 1130, pp. 262-266.

9. Najafi, M.; Yousefi, Y.; Rafati, A.A. Synthesis, characterization and adsorption studies of several heavy metal ions on amino-functionalized silica nano hollow sphere and silica gel. Separation and Purification Technology, 2012, 85, pp. 193-205.

10. Badley, R.D.; Ford, W.T.; McEnroe, F.J.; Assinks, R.A. Surface modification of colloidal silica. Langmuir, 1990, 6, pp. 792-801.

11. Bergna, H.E. Ed. The Colloid Chemistry of Silica Advances in Chemistry Series 234, American Chemical Society: Washington, DC, 1994; pp. 83-111.

12. Van Blaaderen, A.; Vrij, A. Synthesis and characterization of monodisperse colloidal organo-silica spheres. Journal of Colloid and Interface Science, 1993, 156, pp. 1-18.

13. Melnyk, I.V.; Tomina, V.V.; Zub, Yu.L. Synthesis submicro-and nanoscale spherical silica particles with 3-aminopropyl groups in the surface layer. The 3rd International Conference Nanomaterials: Application and Properties, 16-21 September, 2013: Proceedings of the international conference nanomaterials: applications and properties, Alushta, the Crimea, Ukraine, 2(1), pp. 02PCN40-1 -02PCN40-3.

14. Berriozabal, G.; R. de Miguel, Y. Synthesis and characterisation of silica nanoparticles bearing different functional groups obtained via a two-stage method. Physica Status Solidi C 7, 2010, 11-12, pp. 2692-2696. 